\title{
Medico-Legal Aspects of Covid-19: Microbial Terrorism
}

\author{
Ekampreet Kaur ${ }^{1}$, Jaskaran Singh ${ }^{2}$, Neeta Raj Sharma ${ }^{3}$ \\ ${ }^{1}$ Masters of Forensic Science Student, Department of Forensic Science, Punjabi University, Patiala, Punjab, India \\ ${ }^{2}$ Head of Department and Assistant Professor, Department of Forensic Science, School of Bioengineering and Biosciences, Lovely \\ Professional University, Phagwara, Punjab, India. \\ ${ }^{3}$ Professor, Additional Dean, School of Bioengineering and Biosciences, Lovely Professional University, Phagwara, Punjab, India.
}

\begin{abstract}
The entire world is going through hard times because of the emergence of new pandemic named Coronavirus or COVID-19. The virus originated from Wuhan and has spread Worldwide. There are many questions arising regarding the origin of this fatal virus; whether it is natural or manmade. In the past years, many microorganisms were used as biowarfare agents for causing destruction. In 2001, anthrax attack took place in United States (US) by the use of bacteria, Bacillus anthracis which acted as a bioweapon and led to a number of deaths in Texas, US. This review summarises the origin, epidemiology, medico-legal aspects and the recent researches of the virus indicating its nature of being manmade or a natural virus.

Keywords: COVID-19, Identification, Epidemiology, Diagnosis, Bioweapon.
\end{abstract}

Int J Eth Trauma Victimology (2020). DOI: 10.18099/ijetv.v6i02.7

\section{INTRODUCTION}

A newly emerged virus in the year 2019 is named Corona Virus (2019-nCoV) by World Health Organisation (WHO). It was discovered in 1960 and firstly reported in December 2019 when a tremendous number of pneumonia cases was reported in Wuhan, China. As a result, etiological research was carried out by the government of China for taking preventive measures to control this epidemic. ${ }^{1}$ It is genomically analyzed and suggested that a strain of CoV (2019 n-CoV) has been named as Severe Acute Respiratory Syndrome CoV-2 (SARS- CoV-2) recently. This viral infection was suspected to be zoonotic in origin. ${ }^{2}$ Coronavirus causes infection in respiratory and intestinal tracts in humans and non-humans.

In 2002-03 serious upsurge of severe acute respiratory disorder in the Guandong province of China made it highly pathogenic to humans. Familial mass of pneumonia upsurge append to the evidence of pandemic COVID-19. The graph of this disease is reaching heights because of human to human transmission of this viral disease. ${ }^{3}$ Infectious Bronchitis virus (IBV) was the first discovered $\mathrm{CoV}$ in chickens and human CoVs, causing respiratory diseases. Common cold in humans was caused by CoV-OC43 (HCoV-OC43). SARS CoV in 2002 was discovered after the arrival of $\mathrm{HCoV}-229 \mathrm{E}$ and $\mathrm{HCoV}$ OC43. ${ }^{4}$

\section{Diversity of Coronavirus}

Coronavirus belongs to subfamily corona virinae and member of corona viridae family and order Nidovirales as given by the International Committee on Taxonomy of Viruses. According to the studies, it is found that four genera of this subfamily are there namely, Alphacoronavirus, Betacoronavirus, Gammacoronavirus and Delta coronavirus. These subfamilies are designated based on their genomic structure along with the phylogenetic relationship. ${ }^{5}$
Corresponding Author: Dr. Jaskaran Singh, Head of Department and Assistant Professor, Department of Forensic Science, School of Bioengineering and Biosciences, Lovely Professional University, Phagwara, Punjab, India, e-mail: jaskaran.22220@lpu.co.in

How to cite this article: Kaur E, Singh J, Sharma NR. MedicoLegal Aspects of Covid-19: Microbial Terrorism. Int J Eth Trauma Victimology 2020;6(2):26-30.

Source of support: Nil

Conflict of interest: None declared

Received: 06/10/2020; $\quad$ Received in revised form: 11/12/2020; Accepted: $14 / 12 / 2020$ Published:25/12/2020

Respiratory illness and gastroenteritis are caused by alpha and beta corona viruses in humans and animals. A study claimed that Betaconona virus infects only mammals. Gamma and Delta coronaviruses affect the bird species, but some of them are reported fatal for mammals also. These two genera of coronavirus induce mild upper respiratory diseases in the immuno-competent host. ${ }^{6}$

\section{Structure of Coronavirus}

This newly popped SARS-CoV-2 is a single-stranded ribonucleic acid (RNA) having a spherical structure consisting of spike proteins. Coronavirus is alleged so because the word corona is derived from Latin word corona, which means 'crown'. The virus has a royal crown-like appearance when it is observed under an electron microscope. The $\mathrm{CoV}$ is protected by a lipid bilayer and consists of certain proteins, namely, spike $(\mathrm{S})$ protein, nucleocapsid $(\mathrm{N})$ protein, membrane $(\mathrm{M})$ protein, envelope (E) protein, and haemagglutinin esterase (HE). ${ }^{7}$ This haemagglutinin esterase protein increases the admittance and pathogenicity of the coronavirus. SARS-CoV-2 has an identical structure as that of coronavirus, including other constituents like poly-proteins, nucleoproteins, membrane proteins like RNA polymerase. Other enzymes present in 
this virus include helicase, glycoprotein, accessory proteins, 3-chymotrypsin - like protease. It is studied that SARS - CoV-2 having spike protein consist of $3-\mathrm{D}$ structure. ${ }^{6}$

\section{IDENTIFICATION OF Covid-19}

Coronavirus is a contagious disease; it is imperative to find the root cause of this epidemic. Dr. Zhengli Shi, also known as "Bat Women" from the Wuhan Institute of Virology and Biosafety, was one big suspect in this matter. She was suspected of being a creator of this virus. She was working on an experiment with her colleagues in which she did mutation of amino acid so that it got compatible with the SARS virus. Moreover, she had published many articles related to the SARS virus. $^{7}$ On $3^{\text {rd }}$ February 2020, Dr. Zhengli Shi claimed that the Wuhan virus is of bat origin. Liu et al. detected SARS$\mathrm{CoV}$ from Pangolin lung samples (2020). According to their

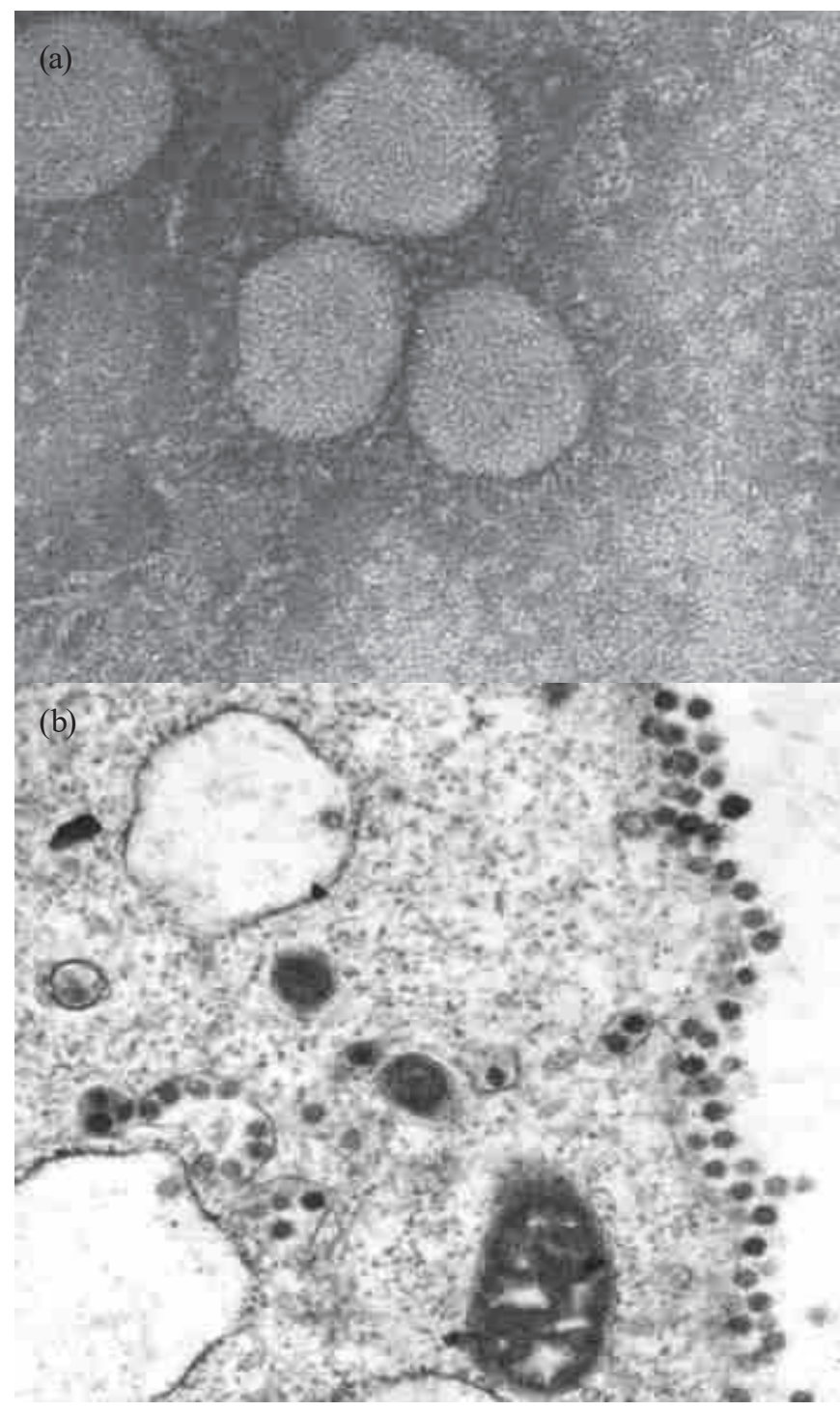

Figure 1: (a) and (b) Microscopic view of Coronavirus.

Source: Department of Microbiology, University of Hong Kong and the Government Virus Unit, Department of Health, Hong Kong SAR China. study, dead Malayan Pangolins were carrying genomic as well as Darwinism evidence of a presence of identical $\mathrm{CoV}$ like that of SARS-CoV-2, namely Pangolin (Co-V). Pangolin $\mathrm{CoV}$ showed the most identical features with SARS-CoV-2 beside RaTG13. ${ }^{8}$ RNA-sequencing was performed on the lung samples of Pangolins. Furthermore, genomic characteristics of Pangolins were studied to find out the origin. Last but not least, the researchers made a phylogenetic relationship between the suspected animal species like Pangolin-CoV (from pangolin) RaTG13(from rodents), SARS-CoV- $2 .{ }^{8}$

Secondly, bats are also considered as a probable species for the origin of this COVID-19. The study depicted that $96 \%$ of whole-genome sequencing was identical between SARS$\mathrm{CoV}-2$ and CoV of bats. Hence, bats species also came in the list of hosts of zoonotic viruses such as Nipah and Hendra virus. These hosts seldom show any clinical symptoms. The overall nucleotide sequence identity between SL-CoV Rp3 (bat) and SARS CoV Tor 2 was $92 \% .{ }^{9}$ The current database sequence suggests that all human coronavirus have a zoonotic origin. SARS-CoV, HCoV-NL63, HCoV-229E, MERS-CoV originated from bat species. ${ }^{10}$

\section{Physiochemical Properties}

The virus particle is oval-shaped and diameter varying from 60-100 nm (approx.) SARS-CoV, and MERS-CoV together gives information regarding physicochemical properties of CoVs. Ultraviolet light or heating at 56 degrees for 30 minutes inactivates SARS-CoV-2. This virus is also sensitive to chemicals like peracetic acid, chloroform, $75 \%$ ethanol, diethyl ether. This virus remains for 72 hours on surface like plastic and stainless steel. ${ }^{11}$

\section{Genomic Variation}

Earlier, a study depicted that the largest RNA among all viruses is of coronavirus containing approx. 27-30 kb. Six to seven regions are present in a genome of a virus and all of them are well organized. Each region consists of one or more open reading fragmentss and are separated by junction sequence containing signals. These signals aid in the transcription of multiple sub-genomic mRNA's. ${ }^{12}$ A recent study has described that RNA genome of $\mathrm{CoV}$ is the second largest in RNA viruses; largest genome is of Planarian Secretory Cell Nidovirus (PSCNV). It consists of 41.1-kilo base genome size. Structural along with the Non-structural proteins are coded by viral RNA. ${ }^{13}$ There is no interferences of recombinant events. RNA virus is unstable, and hence continuous scrutiny of SARS-CoV-2 spreading human to non-humans is very imperative for controlling the disease. In the entire genome of Wuhan-Hu-1 coronavirus (WHCV), a single strain of SARS - CoV-2 is of $29.9 \mathrm{~kb}$. Moreover, the studies have suggested that the genome of CoVs contain fluctuating numbers of open reading frames (ORFs) ranging from 6-11. The positive sense RNA of SARS-CoV and MERS-CoVshows genomes of $27.9 \mathrm{~kb}$ and $30.1 \mathrm{~kb}$, respectively. ${ }^{13}$ High mutation rates characterize all RNA viruses, the evolution of CoVs and transmission 
from one species to another. Results and analysis by various researchers have proved that SARS and MERS- CoVs have emerges from ancestral CoVs nurtured by bats. It has been reported that animals are considered as intermediate hosts, and humans are terminal hosts. ${ }^{6}$

\section{Epidemic to Pandemic}

On 29th December 2019 four patients of acute respiratory syndrome were reported in Wuhan city of China. Wuhan Health Commission (WHC) reported that there is linkage of this virus with that of local seafood market. The Wuhan Institute of Virology of China claimed that out of 33, 585 environmental samples contained coronavirus nucleic acid depicting that this virus has emerged from the wild animals from that local market. ${ }^{14}$ In China, there were 11791 confirmed cases of coronavirus and 17988 suspected cases in 34 cities of China (as of $31^{\text {st }}$ January 2020). A total of 213 deaths were reported globally since then. This epidemic was converted into a pandemic when the virulent disease affected 19 more countries all over the world. COVID-19 was regarded as a contagious disease. The identification, diagnosis, clinical course, management of this viral disease was done when this disease affected the US province. Globally, the positive cases as on 16th February 2020 were 51,857 in 25 countries as claimed by the World Health Organization (WHO). ${ }^{15}$

\section{Is Covid-19 a Biological Weapon?}

In the past years, many microorganisms have been reported which have caused pandemic in the world. These microbes include; Plague Salmonella, Anthrax, and H5N1. COVID-19 is just one more epidemic that is spreading worldwide like a forest fire. The main reason behind this is that it is spread by human to human transmission hence; it is regarded as contagious in nature. Recent researches suggested that this virus is contagious even when the person does not show any symptom. The similarity between all the epidemics is that they are global and cause widespread destruction all around. One cannot deny the fact that these epidemics go hand in hand with globalization and has a barbarous effect on the economy, trade and tourism.This pandemic has been originated from Wuhan and affected the entire world. People are looking for

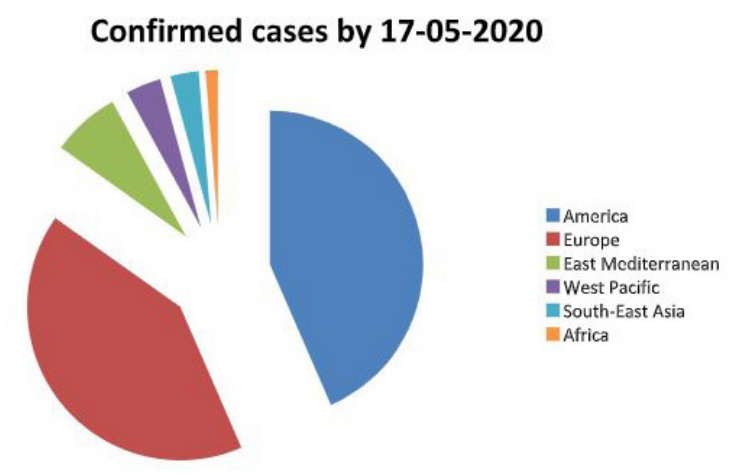

Figure 2: Confirmed cases of COVID-19 till 17th May, 2020 Source : WORLD HEALTH ORGANIZATION (WHO) the reasons for the outbreak of these epidemics. It is sceptical that this deadly coronavirus affected the world in the short time span. It can be opined that SARS-Cov-2 is a manmade virus. Virola virus was not manmade; it undergone certain mutations and then got transferred into humans. So, it might be possible that COVID-19 might be a genetically modified virus, or it may be a recombinant virus. ${ }^{16}$

\section{Clinical Analysis}

Yelin et al. used a pooling approach for standard RT-qPCR for evaluation of COVID-19. The researchers used swabs from the nostrils, throat for the analysis. Pooling works in conjugation with RT-qPCR but it gives 10\% false negative results. ${ }^{17}$ Muhammad Farooq along with his co-worker Abdul Hafeez used radiographs for the analysis and claimed that chest X-rays of patients infected by COVID-19 depicted certain abnormalities in radiography. ${ }^{18}$ Hence, Laboratory detection of this virus included certain clinical findings like genome sequencing, RT-PCR technique and Serological methods like enzyme linked immunosorbent assay (ELISA). This method was based on SARSr - CoVRp3 nucleocapsid protein and was created to ascertain the immunoglobulins IgM and IgG. But the drawback came out when this test gave false positive results among human beta-coronavirus genus. ${ }^{16}$

\section{Vaccines and Drugs}

The viruses which are affecting the world severely with devastating effects include Ebola virus, Nipah virus, Zika virus have started a race of exploring and designing of new vaccines, drugs, therapeutics to get cure of these diseases. Many drugs and agents are detected under clinical trial by following adequate protocols, but efficacy has not yet been established for any drug therapy.

\section{Remdesivir}

It is an antiviral drug manufactured by Gilead sciences. It inhibits the replication of virus, and this drug is proved commendable for MERS-infected rats and monkeys.

Latest World Economic Outlook Growth Projections

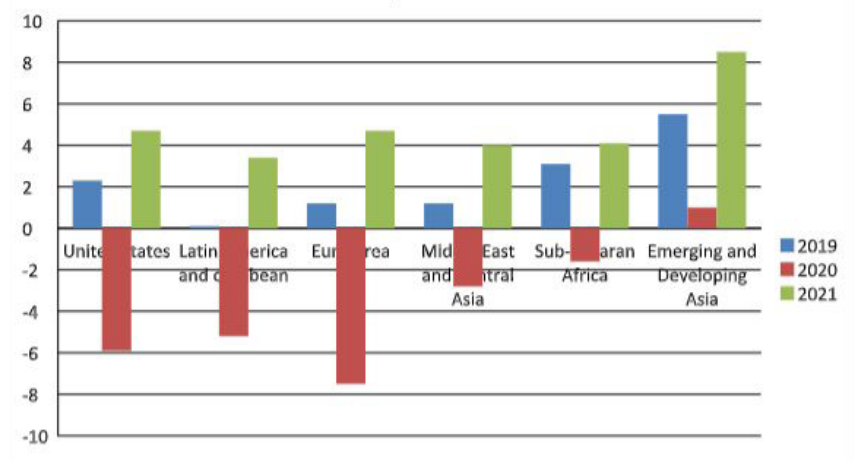

Figure 3: Graph depicting GDP of various countries. Source: International Monetary Fund (IMF) 
Table 1

\begin{tabular}{|c|c|c|c|}
\hline & 2019 & 2020 & 2021 \\
\hline United States & 2.3 & -5.9 & 4.7 \\
\hline Euro Area & 1.2 & -7.4 & 4.7 \\
\hline Latin America and The Caribbean & 0.1 & -5.2 & 3.4 \\
\hline Sub-Saharan Africa & 3.1 & -1.6 & 4.1 \\
\hline Middle East and Central Asia & 1.2 & -2.8 & 4.0 \\
\hline Emerging and Developing Asia & 5.5 & 1.0 & 8.5 \\
\hline WORLD & 2.1 & -3.0 & 5.8 \\
\hline
\end{tabular}

Source: International Monetary Fund (IMF)

\section{Favilavir}

Favilavir is the first drug approved for coronavirus in China. It is licensed as an experimental drug, and research is still going on for the effectiveness of this drug.

\section{Lopinavir; Ritonavir}

This drug is Human immunodeficiency virus (HIV) Protease inhibitor. It suppresses the coronavirus activity by binding with an enzyme which helps in coronavirus replication.

\section{Covid-19 Convalescent Plasma}

The blood plasma samples accumulated from patients retrieved from the viral disease, which might consist of antibodies against SARS-CoV-2.

\section{Hydroxychloroquine}

Hydrochloroquine is an anti-malarial drug. Clinical trials performed in China showed potency and pertinent protection by these drugs countering COVID-19 linked pneumonia.

\section{Immune System Booster}

Vitamin $\mathrm{C}$ and $\mathrm{B} 6$ are recommended for enhancing immunity. Vitamin B6 is important to sustain biochemical reactions. Vitamin $\mathrm{E}$ also act as an antioxidant and helps in fighting against infections.

Currently, no such drug, vaccine has been made to cure COVID-19. ${ }^{19}$

\section{Medicolegal Repercussion}

The people infected by the coronavirus were kept under check to ascertain the symptoms caused by this disease. A study done in Wuhan, China, revealed that the major symptoms at the inception of illness were fever. A total of $98 \%$ of the sufferers were suffering from acute fever. A total of $76 \%$ of affected people were having cough. Fatigue was also a parameter that was proved as a major symptom. More than half of the patients were suffering from dyspnea. ${ }^{20}$ Other Symptoms that were rarely present included headache, diarrhea, and hemoptysis. ${ }^{21}$ A study performed in hospitals of Wuhan proposed that hospital-related transmission of s2019-nCoV was doubtful in $41 \%$ of patients, and the mortality rate came out to be $4.3 \%$. Adults and infants were subjected more to this viral disease and required ICU care. ${ }^{22}$ Currently no vaccine has been made to cure this contagious disease. The safest way to get rid of this disease is to avoid viral exposure. ${ }^{6}$

\section{Wuhan Coronavirus: Manmade or ReCOMBINANT}

Wuhan coronavirus is strangely identical to 2 bat; ZC45 and ZXC21 as revealed by a study. Recombination has to take place twice during evolution of Wuhan coronavirus. The ancestor bat corona virus had to acquire through recombination with SARS like coronavirus. ${ }^{20}$ On $2^{\text {nd }}$ January 2020 Director-General of Wuhan Institute of Virology released a notice regarding the strict prohibition and disclosure of any information regarding this disease. There were a number of news and articles published against Wuhan Institute of Virology regarding origin of coronavirus from this lab. ${ }^{7}$ Through all the news and instances, COVID-19 doesn't seem to be a natural virus. There are lots of queries and conjectures on its mutation and manmade interventions.

\section{Conclusion}

- COVID-19 has proved to be a threatening virus. It is a pandemic which is spreading devastation all over the world. There are many controversies regarding the origin and spreading of this disease. The world is facing a severe crisis due to fall in economic GDP and globalisation along with high fatality rate.

- COVID-19 might be a Bio-warfare agent which has caused gigantic demolition in the world.

\section{REFERENCES}

1. Sun P, Lu X, Xu C, Sun W, Pan B. Understanding of COVID-19 based on current evidence. J Med Virol. 2020;92(6):548-551.

2. Dhama K, Sharun K, Tiwari R, Dadar M, Malik YS, Singh KP, et al. COVID-19, an emerging coronavirus infection: advances and prospects in designing and developing vaccines, immunotherapeutics, and therapeutics. Hum Vaccines Immunother. 2020;1-7.

3. Guo Y-R, Cao Q-D, Hong Z-S, Tan Y-Y, Chen S-D, Jin H-J, et al. The origin, transmission and clinical therapies on coronavirus disease 2019 (COVID-19) outbreak-an update on the status. Mil Med Res. 2020;7(1):1-10.

4. Ashour HM, Elkhatib WF, Rahman M, Elshabrawy HA. Insights into the recent 2019 novel coronavirus (SARS-CoV-2) in light of past human coronavirus outbreaks. Pathogens. 2020;9(3):186. 
5. Adhikari SP, Meng S, Wu Y-J, Mao Y-P, Ye R-X, Wang Q-Z, et al. Epidemiology, causes, clinical manifestation and diagnosis, prevention and control of coronavirus disease (COVID-19) during the early outbreak period: a scoping review. Infect Dis Poverty. 2020;9(1):1-12.

6. Cui J, Li F, Shi Z-L. Origin and evolution of pathogenic coronaviruses. Nat Rev Microbiol. 2019;17(3):181-192.

7. Goyal VK, Sharma C. The novel coronavirus 2019: A naturally occurring disaster or a biological weapon against humanity: A critical review of tracing the origin of novel coronavirus 2019.

8. Zhang T, Wu Q, Zhang Z. Probable pangolin origin of SARSCoV-2 associated with the COVID-19 outbreak. Curr Biol. 2020;

9. Zhou P, Yang X-L, Wang X-G, Hu B, Zhang L, Zhang W, et al. A pneumonia outbreak associated with a new coronavirus of probable bat origin. nature. 2020;579(7798):270-273 .

10. Li W, Shi Z, Yu M, Ren W, Smith C, Epstein JH, et al. Bats are natural reservoirs of SARS-like coronaviruses. Science. 2005;310(5748):676-679.

11. Jin Y, Yang H, Ji W, Wu W, Chen S, Zhang W, et al. Virology, epidemiology, pathogenesis, and control of COVID-19. Viruses. 2020;12(4):372.

12. Spaan W, Cavanagh D, Horzinek MC. Coronaviruses: structure and genome expression. J Gen Virol. 1988;69(12):2939-2952.

13. Shereen MA, Khan S, Kazmi A, Bashir N, Siddique R. COVID19 infection: Origin, transmission, and characteristics of human coronaviruses. J Adv Res. 2020;
14. Rothan HA, Byrareddy SN. The epidemiology and pathogenesis of coronavirus disease (COVID-19) outbreak. J Autoimmun. 2020;102433.

15. Wang Y, Wang Y, Chen Y, Qin Q. Unique epidemiological and clinical features of the emerging 2019 novel coronavirus pneumonia (COVID-19) implicate special control measures. J Med Virol. 2020;92(6):568-576.

16. Jormakka J. Is Covid-19 a bioweapon?

17. Yelin I, Aharony N, Shaer-Tamar E, Argoetti A, Messer E, Berenbaum D, et al. Evaluation of COVID-19 RT-qPCR test in multi-sample pools. MedRxiv. 2020;

18. Farooq M, Hafeez A. Covid-resnet: A deep learning framework for screening of covid19 from radiographs. ArXiv Prepr ArXiv200314395. 2020;

19. Sanapala AK, Namratha S, Junapudi S. Coronavirus Treatment: Newer Therapeutic Development of Covid-19 Drugs and Vaccines.

20. Du Toit A. Outbreak of a novel coronavirus. Nat Rev Microbiol. 2020;18(3):123-123.

21. Huang C, Wang Y, Li X, Ren L, Zhao J, Hu Y, et al. Clinical features of patients infected with 2019 novel coronavirus in Wuhan, China. The lancet. 2020;395(10223):497-506.

22. Wang D, Hu B, Hu C, Zhu F, Liu X, Zhang J, et al. Clinical characteristics of 138 hospitalized patients with 2019 novel coronavirus-infected pneumonia in Wuhan, China. Jama. 2020;323(11):1061-1069. 